Mommy. Direção de Xavier Dolan. Brasil: Paramount Pictures, 2015 (138 $\min )$.

\title{
Liberdade, liberdade e contemporaneidade
}

Fernanda Canavêz ${ }^{1}$

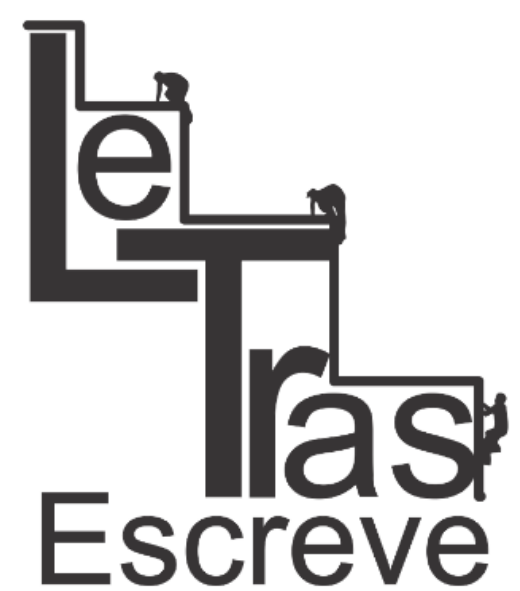

(ISSN 2238-8060) assim preconizasse.
É desse modo que somos convidados a assistir ao fantástico Mommy, cujo sugestivo título apresenta uma complexa relação entre mãe e filho, exatamente como vínculos maternais sabem ser. Aliás, Dolan, apesar da pouca idade, já coleciona títulos igualmente intensos e de análises nada superficiais como as travadas com as mães exigem, dentre os quais o polêmico Eu matei minha mãe (2009). Com efeito, "Só as mães são felizes", diria o nosso Cazuza, "não podem mudar a vida".

Diane, uma das mães protagonistas no filme em questão, materializa essa figura da guerreira que não pode mudar a vida, com quem o destino não teria sido muito cordial: é abandonada à própria sorte pela morte prematura do pai de seu filho, que acaba por ser deixado em um abrigo onde incendeia o refeitório, episódio de corte que faz com que Diane o busque para morar novamente em sua companhia.

\footnotetext{
1 Professora do Departamento Universidade de Psicologia (DEPSI/UFRRJ) e do Programa de Pós-Graduação em Psicologia da Universidade Federal Rural do Rio de Janeiro (PPGPSI/UFRRJ), Doutora em Teoria Psicanalítica pela Federal do Rio de Janeiro (PPGTP/UFRJ), fernandacanavez@gmail.com.
} 


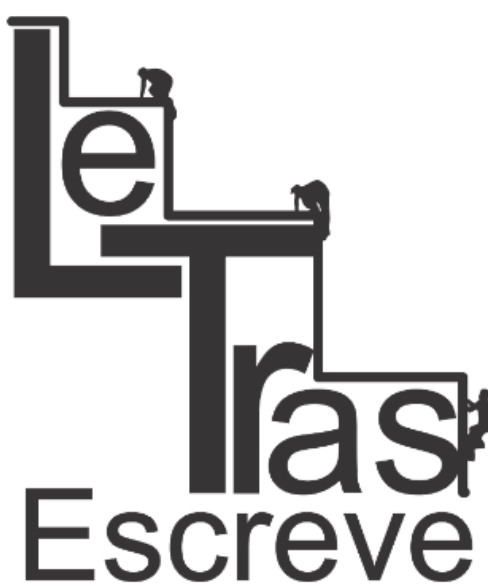

(ISSN 2238-8060)

Steve, personagem de 15 anos cuja adolescência é colorida em tintas carregadas de intempestividade, seria portador do chamado déficit de atenção, ficando clara no filme sua trajetória de percalços escolares, não menos evidente que uma experiência de certo "desajuste". De início o adolescente parece inapto para se adequar socialmente, mas Dolan é exitoso ao produzir no espectador a própria experiência de desajuste, a essa altura já a extrapolar os limites dos traços de personalidade desta ou daquela personagem para caracterizar o próprio encontro com o outro, revestido de avanços e recuos, tropeços e surpresas.

Com o fiar dos novelos das relações dos protagonistas, somos convidados a abandonar certa posição de Simão Bacamarte (ASSIS, 1979), firme e forte na contenda de estabelecer os limites entre a razão e a loucura, disposto a relegar ao limbo institucional aquele que demonstrasse o menor sinal de disfunção aos olhos de quem avalia: quem deveria ser institucionalizado, e por qual fragilidade?

As relações tecidas parecem precárias, mas também (ou talvez por isto mesmo) incrivelmente potentes. Steve passa do déficit de atenção à atenção redobrada dispensada a Kyla, vizinha para quem não se dirigiam mais olhares de cuidado. À vizinha impossibilitada de lecionar devido a "problemas psicológicos" Steve restitui a possibilidade da transmissão. Temos mais uma protagonista mãe, para cuja filha biológica não restam muitas possibilidades de trocas afetivas, marcada que essa relação é pelo enquadre opressivo de uma família refém de um ideal aos moldes da tradição. Podemos aceitar o convite de Dolan à fantasia e depreender que talvez o cotidiano de Kyla em uma escola marcadamente disciplinar tenha contribuído para lhe tirar a voz - um "distúrbio da fala" é um de seus sintomas -, restituída agora pela potência afetiva que o encontro com Steve e sua mãe Ihe desperta.

A trajetória de fracasso escolar de Steve é transformada em uma intensa relação com a vizinha professora, em que esta pode se 


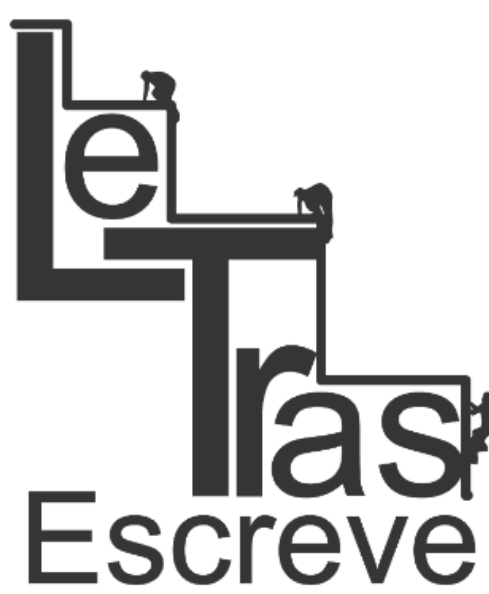

(ISSN 2238-8060)

experimentar novamente no lugar de transmissão da docência, oferecendo ao adolescente a possibilidade de sentir o prazer do aprendizado de um novo mundo que se descortina para além dos muros da escola. Um mundo que requer limites, regras, mas também por isso permite alçar voos mais autônomos, o que a relação entre Steve e sua mãe parecia claudicar em fazer operar. Steve, por sua vez, oferece a Kyla um espaço de fala, espaço-tempo de experimentação para além dos muros do papel de mãe de família tradicional canadense que dela se esperava. Kyla fala, ensina e, quem diria, até canta.

Embora não seja de saída a relação em cuja tônica recai a narrativa do filme, Steve e Kyla mostram de maneira mais evidente que, muito mais do que identidades cristalizadas, somos providos de fagulhas identitárias sujeitas ao olhar do outro. Steve moldou-se de acordo com o cuidado a ele dispensado por Kyla, quem reassumiu seu desejo de transmissão a partir do investimento feito no adolescente, em uma via afetiva de mão dupla. Sobre esse aspecto, Freud (1923-1976) asseverou que o eu é um precipitado de identificações abandonadas, destacando a dimensão desde sempre alteritária em jogo na constituição subjetiva. Ao contrário do que pode nos fazer crer uma sociedade em que impera o franco avanço do individualismo, somos sempre em relação, sujeitos relacionais sensíveis ao olhar e ao investimento do outro. E se com esse outro podemos ter bons encontros, é também em quem podemos enxergar a expectativa de adequação a determinados modelos que colocam em xeque nossa dimensão múltipla, como precipitado de identificações.

Em uma das cenas mais impactantes, Steve voa com um pássaro do alto das rodas de seu skate e de sua peculiar sensibilidade ao som de Wonderwall, da banda inglesa Oasis. "Liberdade! Liberdade!" - brada o adolescente nos convidando à uma revolução particular que não endereça seus esforços aos desvarios da monarquia absolutista de outrora, mas à tirania do 


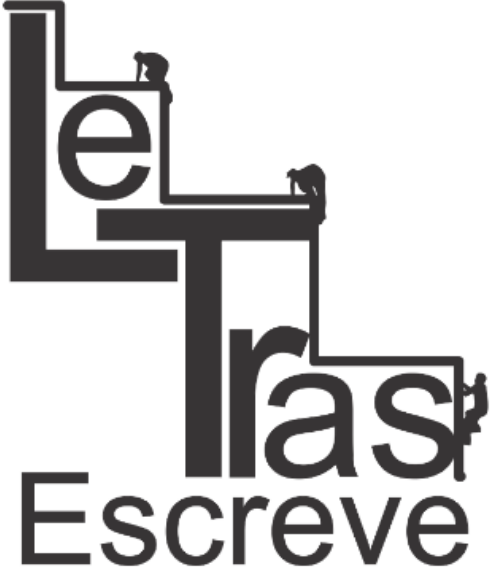

(ISSN 2238-8060) imperativo de um determinado modelo de aluno, de filho e, em última instância, de identidade que a todos oprime. Talvez esta seja a revolução particular a qual todos somos convocados na contemporaneidade: contra as tiranias identitárias que a modernidade em sua lógica disciplinar ajudou, com esmero, a construir.

No sentido do apelo à liberdade, o filme é oportuno para trazer à baila o tema da medicalização da vida, que faz sentir seus efeitos também no campo da Educação. A medicalização apresenta diferentes definições a depender do contexto estudado, mas para os efeitos da presente resenha a compreenderemos seguindo as pistas de Conrad (1992), qual seja, como um processo sociocultural que busca reduzir questões complexas a toda uma lógica e terminologia médicas na expectativa de controlar o comportamento tido como desviante. Em adição, pode ainda ser compreendido como processo de apropriação de fatos cotidianos por parte da tecnologia médica, como se a esta tivessem que ser reservados (CONRAD, 2007). Cumpre esclarecer que a medicalização é comumente confundida com o processo de medicação, mas a este não se reduz, muito embora tenha nele uma expressiva evidência.

No Brasil, há um aumento absoluto expressivo do consumo de metilfenidato nos últimos anos, substância psicoestimulante aprovada para o tratamento do transtorno do déficit de atenção e hiperatividade (TDAH), cuja prescrição nem sempre considera a sobredeterminação de fatores que podem concorrer o chamado fracasso escolar. Segundo a Anvisa (2012), "o medicamento deve funcionar como coadjuvante no estabelecimento do equilíbrio comportamental do indivíduo, aliado a outras medidas, como educacionais, sociais e psicológicas" (p. 13). Em Mommy o furor diagnóstico levaria à institucionalização, destino que acabou por encarcerar os voos mais ousados de Steve, seduzida que sua mãe foi por um ideal de filho: o que cursa uma "boa" universidade, casase com uma "boa" esposa, torna-se um "bom" pai de família. No

https://periodicos.unifap.br/index.php/letras Macapá, v. 6, n. I, Io semestre, 2016. 


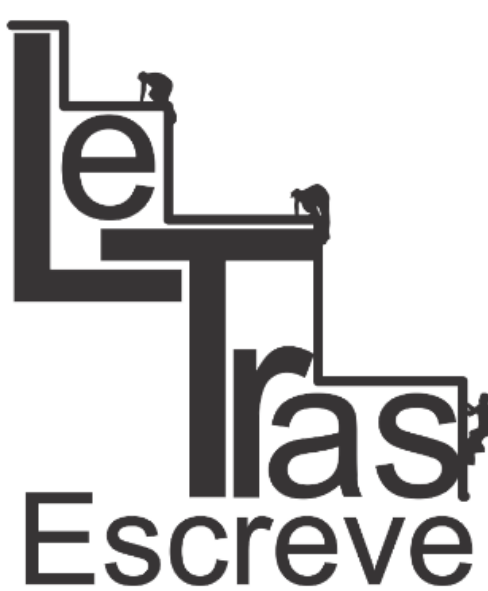

(ISSN 2238-8060)

Canadá judicializado aventado por Dolan, à sensibilidade que escapa a todas essas roupagens só resta o engessamento institucional.

O cenário construído por Dolan parece distante da realidade brasileira, dados os avanços da Reforma Psiquiátrica em Terra Tupiniquim. A Reforma busca reordenar o serviço oferecido em Saúde Mental, problematizando o modelo hospitalocêntrico que o caracterizou historicamente a assistência dispensada ao paciente portador de transtornos psiquiátricos em nosso país para favorecer serviços substitutivos ao hospital psiquiátrico, como prevê a Lei Federal 10.216, de 2001 (BRASIL, 2001). Na esteira das críticas endereçadas a uma lógica calcada na exclusão das diferenças, coloca-se em pauta a discussão de uma forma de atuação que não esteja a serviço da estigmatização em detrimento do cuidado.

Sendo assim, no Brasil os louros da Reforma Psiquiátrica (ou seria a patrulha do politicamente correto?) ainda nos permitem manter as formas mais explícitas de Simão Bacamarte nas prateleiras da caricatura, mas nosso furor diagnóstico a todos nos toma de assalto em nossas afonias, disfunções e, em última instância, formas de resistir às injunções disciplinares. Se Machado de Assis pudesse revisitar sua Casa Verde dos tempos de outrora, talvez não se tratasse de uma instituição com endereço fixo e portas trancadas, mas quem sabe uma rede social onde todos a todos vigiam e não raras vezes somos interpelados por uma patrulha identitária. "Defenda-se no tribunal do feicebuqui", ganha voz com o brilhante Tom Zé.

Quem pode se ver inteiramente livre do furor classificatório disposto a enquadrar como patológico todo e qualquer desvio que escape a um ideal paradoxalmente ascético de relação, desempenho e saúde? A página inicial de uma das maiores redes sociais da atualidade traz os seguintes dizeres: "No facebook você pode se conectar e compartilhar o que quiser com quem é importante em sua vida". Há tempo suficiente para entender o que 


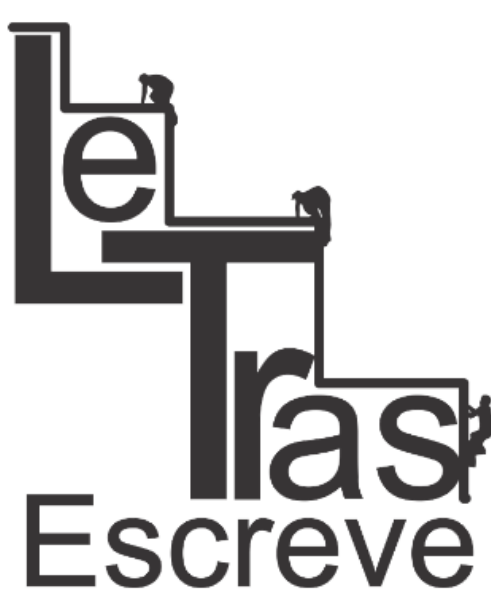

(ISSN 2238-8060)

queremos compartilhar e quem importa em nossas vidas líquidas ${ }^{2}$ no compasso de curtidas e de bombardeios imagéticos a serviço de um ideal de relação, desempenho e saúde em relação ao qual parecemos estar sempre em débito? Liberdade! Liberdade! é um apelo que continua tão ou mais importante, na medida em que nos fazemos algozes de nós mesmos na busca desenfreada por nos fazer encaixar em identidades (tantas vezes medicalizadas) que, de antemão, são capazes de nos trancafiar em nossas casas verdes psíquicas.

Mommy é novamente genial ao trazer uma cena em que os três protagonistas cantam e dançam ao som de On ne change pas, hit de Céline Dion. "Nós não mudamos", diz a canção, "apenas vestimos as roupas dos outros", "apenas nos escondemos de nós mesmos por um momento". Um verdadeiro elogio à potência do "desajuste" e dos encontros que este pode proporcionar, burlando os imperativos dos enquadres disciplinares para flanar de acordo com o termômetro dos afetos.

\section{Referências Bibliográficas}

AGÊNCIA DE VIGILÂNCIA SANITÁRIA - ANVISA. Prescrição e consumo de metilfenidato no Brasil: identificando riscos para o monitoramento e controle sanitário. Boletim de Farmacoepidemiologia do SNGPC, ano 2, n. 2, p. 1-14, 2012.

ASSIS, M. O Alienista. In: . Obra Completa. Vol. II. Conto e Teatro. Rio de Janeiro: Nova Aguilar, 1979, p. 253-288.

BAUMAN, Z. Vida líquida. Rio de Janeiro: Jorge Zahar, 2007. BRASIL. Lei 10.216, de 06 de abril e 2001. Diário Oficial da União, Poder Executivo, Brasília, DF, 9 abr. 2001.

\footnotetext{
2 Por alusão ao termo "vida líquida", cunhado pelo sociólogo Zigmunt Bauman (2007) para caracterizar a fluidez característica da experiência subjetiva na contemporaneidade.
}

https://periodicos.unifap.br/index.php/letras

Macapá, v. 6, n. I, Io semestre, 2016. 
CONRAD, P. Medicalization and Social Control. Annual Review of Sociology, v. 18, p. 209-232, 1992.

. The medicalization of society: on the transformation of

human conditions into treatable disorders. Baltimore: The Johns Hopkins University Press, 2007.

FREUD, S. O ego e o id. In: Edição Standard Brasileira das

Obras Psicológicas Completas, Vol. XIX. Rio de Janeiro: Imago, p. 13-89, 1923-1976.

Recebido em 01/02/2016. Aprovado em 10/03/2016.

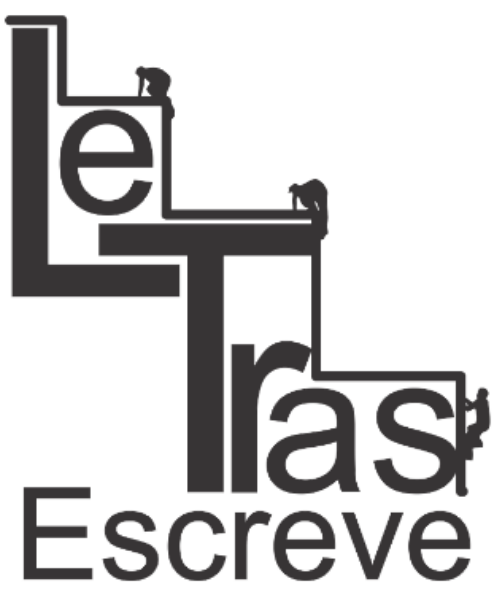

(ISSN 2238-8060) 